\title{
Morfología Testicular del Yaque Leiarius marmoratus (Pisces: Siluridae) en Estadio de Madurez Reproductiva
}

\author{
Testicular Morphology of Yaque Leiarius marmoratus \\ (Pisces: Siluridae) in Maturity Reproductive Stage
}

Tatiana M. Mira López; Víctor M. Medina-Robles \& Pablo E. Cruz-Casallas

\begin{abstract}
MIRA, L. T. M.; MEDINA-ROBLES, V. M. \& CRUZ-CASALLAS, P. E. Morfología testicular del yaque Leiarius marmoratus (Pisces: Siluridae) en estadio de madurez reproductiva. Int. J. Morphol., 28(2):421-426, 2010.

RESUMEN: El conocimiento de la morfología y fisiología del testículo, permite generar bases para el entendimiento del comportamiento reproductivo de las especies, ya que diferencias anatómicas están relacionadas con el desempeño reproductivo. Con el fin de contribuir al conocimiento biológico y reproductivo del yaque Leiarius marmoratus, fueron analizadas las características anatómicas, morfológicas y funcionales del testículo en animales durante el estado de madurez reproductiva. En L. marmoratus los testículos están ubicados ventralmente a la vejiga gaseosa y presentan numerosas y largas digitaciones que terminan en un conducto espermático. Microscópicamente se encontró que el testículo es espermatogonial irrestricto de tipo tubular, donde la porción anterior presenta actividad espermatogénica, que disminuye en la porción media y desaparece en la región distal, dando paso a tejido glandular con actividad secretora, que actúa como vesícula seminal. Al interior de cada túbulo testicular, se observan cistos que contienen células espermáticas en el mismo estadio de desarrollo. Basados en las características microscópicas, fueron identificados espermatocitos, espermátides y gran cantidad de espermatozoides libres en el lumen. También fueron identificadas células glandulares, tejido muscular liso y tejido epitelial. En el ducto espermático (región media y distal), se encontró abundante secreción acidofílica que en algunas regiones estaba acompañada de espermatozoides libres.
\end{abstract}

PALABRAS CLAVE: Bagre; Histología; Tracto reproductivo; Vesícula seminal.

\section{INTRODUCCIÓN}

El yaque Leiarius marmoratus es un silúrido de la familia de los Pimelodidae, que se distribuye en las cuencas de los ríos Orinoco y Amazonas (Ramírez- Gil \& AjiacoMartínez, 1997). A pesar de ser poco frecuente en las capturas comerciales de estos ríos, es una especie muy apetecida por el buen sabor de su carne (Ramírez- Gil \& AjiacoMartínez) y posee un gran potencial para ser introducida en la producción acuícola.

Existe información escasa acerca de la reproducción en cautiverio del yaque; en Colombia y Venezuela se han reportado experiencias exitosas de producción de juveniles de la especie con fines de cultivo, pero ha sido necesario sacrificar los machos para obtener el semen directamente del testículo debido a la dificultad de extraerlo manualmente (Castillo et al., 2003; Mora \& Kossowski, 2006). Esta característica del yaque, se presenta en otras especies de importancia como el Clarias gariepinus (Viveiros et al., 2001, 2002), en la cual, aún con tratamientos hormonales, esta dificultad persiste (Viveiros et al., 2002). La dificultad para obtener el semen por medio de extrusión manual en algunos bagres ha sido atribuida a factores hormonales y a la anatomía y ubicación del testículo, entre otros (Viveiros et al., 2001, 2002).

Entre las familias y especies de silúridos, el sistema reproductivo del macho presenta diferencias anatómicas que pueden ser parcialmente relacionadas con sus modalidades reproductivas (Mazzoldi et al., 2007). La variabilidad observada se refiere principalmente a diferencias en la superficie del testículo y a la presencia de tejido glandular, que puede formar o no, una vesícula seminal (Mazzoldi et al.; 
Santos et al., 2001). En bagre asiático, se ha reportado que la presencia del tejido intersticial denso, que rodea la región espermatogénica del testículo y la vesícula seminal (tejido glandular), podría estar bloqueando el flujo del semen durante la extrusión manual (Tan-Fermin et al., 1999). En $C$. gariepinus se demostró que la agenesia de la vesícula seminal, inducida con tratamiento hormonal, facilitó la obtención manual del semen (Viveiros et al., 2001).

Por lo anterior, el objetivo de este trabajo fue generar información reproductiva básica a través de la descripción macro y microscópica de la morfología del testículo del yaque y su funcionalidad, que permita generar bases para el entendimiento del desempeño reproductivo de esta especie en cautiverio.

\section{MATERIAL Y MÉTODO}

Morfología general del testículo. Machos adultos de Leiarius marmoratus fueron capturados del ambiente natural, durante la época reproductiva de la especie (mayo - julio) del rio Ariari, municipio de Granada, Departamento del Meta, Colombia. Inmediatamente después de la captura, de cada ejemplar se registró el peso corporal $(\mathrm{kg})$ y su longitud total; posteriormente fueron sacrificados por corte medular. Se disecaron y se realizaron las descripciones in situ de la ubicación y características macroscópicas de la gónada. Los testículos fueron extraídos, medidos, pesados y fijados en formol buferado al $4 \%(\mathrm{pH} 7)$, para contar posteriormente el número y medir la longitud de las digitaciones testiculares. La medición de las digitaciones se realizó por medio de un calibrador digital con $0,01 \mathrm{~mm}$ de precisión. También se extrajo y se pesó el hígado para calcular el índice hepatosomático.
Análisis histológicos. Se disecaron tres machos, previo sacrificio por corte medular, para extraer sus gónadas. Cada testículo fue dividido en tres porciones: craneal, media y distal. Se fijó separadamente cada fragmento testicular en formol buferado al $4 \%(\mathrm{pH} 7)$ y se sometió a procesos histológicos convencionales con inclusión en parafina, cortes de $5 \mu \mathrm{m}$ y tinción con hematoxilina - eosina.

Análisis estadísticos. Diferencias significativas en la longitud de las digitaciones entre las tres regiones del testículo fueron determinadas por medio de una prueba de Tukey, usando análisis de varianza de una vía (ANOVA) previa validación de los supuestos de homogeneidad de varianza y normalidad de los datos. Los valores observados fueron expresados como media \pm error estándar de la media.

\section{RESULTADOS}

Los machos en estado de madurez reproductiva presentaron un índice gonadosomático de $0,41 \pm 0,1$ y un índice hepatosomático de $0,32 \pm 0,03$. No se encontró grasa cavitaria ni contenido estomacal, en los machos disecados.

Morfología general del testículo. Los testículos de yaque Leiarius marmoratus son pareados, digitiformes y están localizados en la cavidad celómica, dorsalmente al tubo digestivo y ventralmente al riñón y a la vejiga gaseosa. Se encuentran adheridos a la vejiga gaseosa mediante una membrana y se fusionan al final de la porción caudal en un ducto espermático común, también digitiforme, que se abre en la papila urogenital. Cada testículo en su región craneal (RC) contiene $73 \pm 7$ digitaciones, en la región media (RM) $91 \pm$ 4 digitaciones y en la región distal (RD), $109 \pm 21$ digitaciones. Estas digitaciones se comunican individual o

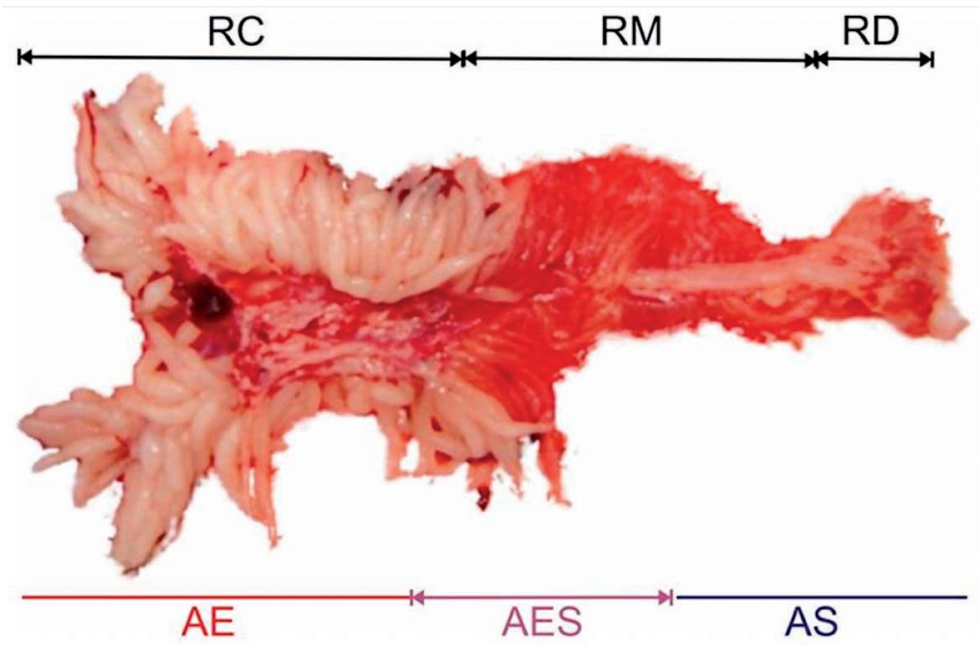

Fig. 1. Testículo maduro de Yaque Leiarius marmoratus con sus regiones anatómicas distintivas: craneal (RC), media (RM) y distal (RD) y regionalización de acuerdo con su funcionalidad: actividad espermatogénica (AE), actividad espermatogénica y secretora (AES) y actividad secretora (AS). 


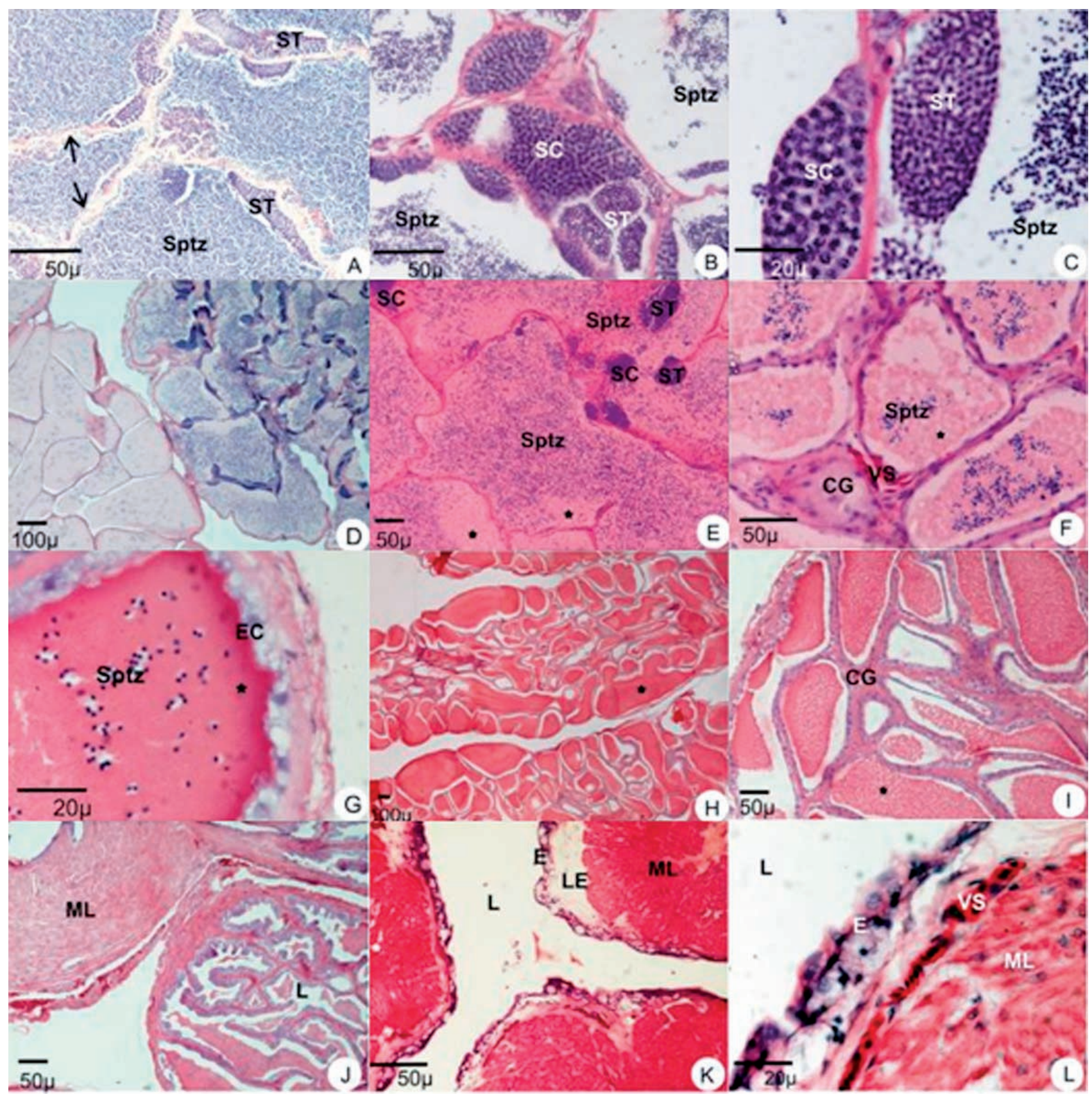

Figura 2. A-C: Actividad espermatogénica de la región craneal (RC) del testículo maduro de Yaque Leiarius marmoratus, con cistos que contienen espermatocitos (SC), espermátides (ST) y espermatozoides (Sptz). Pueden observarse las paredes de los túbulos que componen el testículo $(\rightarrow)$. D-G: Actividad espermatogénica y secretora de la región de transición del testículo maduro de Yaque donde se observan cistos con espermatocitos (SC), espermátides (ST) y espermatozoides (Sptz), células glandulares (CG) y secreción (*). Se observa tejido epitelial simple revistiendo las paredes de los túbulos. H-L: Actividad secretora de la región caudal (RC) del testículo maduro de Yaque donde se observan células glandulares (CG), epitelio simple (E), músculo liso (ML) y secreción (*) en el lumen (L). VS: Vaso sanguíneo, LE: Lámina propia del epitelio.

pareadamente a un ducto espermático común, localizado en la porción ventral de cada testículo. La RC representa el 52 $\%$ de la longitud del testículo maduro y sus digitaciones tienen una longitud de 15,3 \pm 0,2 mm. La RM y RD represen- tan el $35 \%$ y sus digitaciones miden $14,7 \pm 0,2 \mathrm{~mm}$ y el 13 $\%$ con $12,3 \pm 0,1 \mathrm{~mm}$, respectivamente, con diferencias significativas en la longitud de las digitaciones entre las tres regiones. La longitud total del testículo es de 121,7 $\pm 2,2$ 
mm (Fig. 1). Las digitaciones de la RC son de color blanco intenso indicando la presencia de semen, mientras que las de las regiones restantes son de color rojizo y parecen no contener grandes cantidades semen.

Organización histológica. Microscópicamente, el testículo está envuelto por la túnica albugínea que emite septos que penetran en el órgano, formando lóbulos que contienen los túbulos seminíferos. De acuerdo con la clasificación propuesta por Grier (1981), el testículo del yaque es tubular con redes anastomosantes dentro de los túbulos y que contienen epitelio germinal irrestricto. La pared tubular es formada por tejido conectivo y está cubierta por epitelio simple; dentro de los túbulos se encontraron cistos, en cada uno de los cuales fueron observadas células espermáticas en el mismo estadio de maduración. Basados en las características microscópicas, fueron identificados tres tipos de células germinales: espermatocitos, espermátides y espermatozoides (Figs. 2A$2 \mathrm{G}$ ), también fueron encontradas células glandulares, músculo liso y tejido epitelial simple y cúbico (Figs. 2F-2L). La RC se caracteriza por tener alta actividad espermatogénica, observándose en esta región principalmente cistos con espermátides y espermatozoides, así como espermatozoides libres en los lumen testiculares, en menor proporción se observan algunos cistos con espermatocitos (Figs. 2B, 2C, 2E). Esta actividad espermatogénica va disminuyendo a medida que se acerca a la porción caudal. La RM presenta gran cantidad de espermatozoides libres y secreciones acidófilas, estas últimas aumentan y predominan en la RD (Figs. 2H - 2I). El tejido secretor y espermatogénico parece estar ubicado diferencialmente en la RM, esto es, se encuentran digitaciones con espermatozoides y secreciones en el lumen y algunos cistos con espermátides y espermatozoides en la pared de los túbulos y digitaciones que contienen solamente secreciones en el lumen y células glandulares en el intersticio (Figs. 2D, 2I). En la $\mathrm{RD}$, se encontró alta actividad secretora y gran cantidad de células glandulares en la pared tubular con secreción acidófila acumulada en el lumen (Fig. 2I). Las células glandulares predominaron en la porción anterior de la RD, mientras que en la porción posterior, donde comienza la papila urogenital, se observó la presencia de músculo liso y epitelio cúbico y de revestimiento (Figs. 2J - 2L).

Las características histológicas de las diferentes células germinales identificadas en el testículo de L. marmoratus se describen a continuación:

Espermatocitos. Estas células son basófilas y el material nuclear aparece formando masas densas; son las células más grandes encontradas y poseen poco citoplasma (Fig. 2C).

Espermátides. Las espermátides están localizadas a lo largo de los túbulos, en cistos, son más pequeñas y densas que los espermatocitos y tienen citoplasma acidófilo escaso (Fig. 2C).

Espermatozoides. Los espermatozoides son las células más pequeñas y densas encontradas; se tiñen de color azul oscuro y una vez liberadas, se localizan en el lumen, formando grandes masas (Figs. 2A - 2C).

\section{DISCUSIÓN}

El valor del índice gonadosómatico (IGS) variará dependiendo de la especie y del estado de madurez sexual del individuo. El IGS encontrado fue menor a $1 \%$ y se ha documentado que para salmónidos, puede variar desde $0,05 \%$ en machos inmaduros hasta $10 \%$ en machos maduros, mientras que para otras especies tropicales puede variar alrededor 0,2 $\%$ (Billard, 1986; Vizziano et al., 2008). Las variaciones en el índice hepatosomático (IHS) en los peces teleósteos están relacionadas con la capacidad del hígado para almacenar glucógeno, las condiciones fisiológicas, el estado reproductivo y los hábitos y disponibilidad de alimento (Tavares-Dias et al., 2000). Tanto en el IGS como en el IHS, los valores obtenidos en este estudio fueron menores a los encontrados en $I$. Labrosus (Santos et al., 2004).

Entre las familias y especies de silúridos, el sistema reproductivo del macho, presenta diferencias anatómicas que pueden ser parcialmente relacionadas con las modalidades reproductivas (Mazzoldi et al.). La variabilidad observada, se refiere principalmente a diferencias en la superficie del testículo y a la presencia de tejido glandular que puede formar o no, una vesícula seminal (Mazzoldi et al.; Santos et al., 2001). Los testículos de L. marmoratus son digitiformes como ha sido reportado para otros silúridos de la familia Pimelodidae como el Iheringichthys labrosus (Santos et al., 2001, 2004), Pimelodus blochii (Loir et al., 1989), Rhamdia quelem (Loir et al.), Conorhynchus conirostris (Lopes et al., 2004) у Pseudoplatystoma fasciatum (Batlouni et al., 2006), entre otros. Esta característica morfológica, también ha sido reportada en especies de otras familias, dentro las que se destacan, por su importancia económica, miembros de la familia Ictaluridae (Sneed \& Clemens, 1963). El número de digitaciones del testículo de yaque, fue mayor a las presentadas por Santos et al. (2001) para I. labrosus, siendo este el único reporte encontrado en silúridos respecto a esta variable. Las digitaciones fueron más largas que las de el testículo de $I$. labrosus en las tres regiones (Santos et al., 2001).

El testículo del yaque, es espermatogonial irrestricto de tipo tubular y la espermatogénesis se presenta en cistos, donde se observaron células espermatogénicas en estadios sincrónicos de desarrollo, de acuerdo con lo reportado para $P$. 
fasciatum e I. Labrosus (Batlouni et al.; Santos et al., 2001). Los túbulos forman una red anastomosante, característica de las especies de silúridos (Vizziano et al.) como en $L$. marmoratus (este estudio) y en I. labrosus (Santos et al., 2001).

En estado de madurez, la región craneal del testículo de L. marmoratus es espermatogénica, la región medial es espermatogénica y secretora y la región caudal es estrictamente secretora. Los Pimelodidae, Loricariidae, Callichthyidae e Ictaluridae, también tienen esta transición progresiva, presentando tejido testicular en la región anterior, que va dando paso a tejido secretor a medida que se acerca a la región posterior del tracto reproductivo del macho (Grier; Santos et al., 2001; Sneed \& Clemens). La región del testículo del yaque, donde se presenta tanto actividad espermatogénica como secretora, parece estar zonificada, presentándose porciones especializadas donde sólo se puede observar en el interior de los túbulos de cada digitación, secreciones acidófilas mientras que en otras, estas secreciones están acompañadas por espermatozoides y en algunos túbulos pueden observarse además cistos con células espermáticas. Se sugiere entonces, que podrían estar regionalizadas de acuerdo con su funcionalidad, sea secretora o de almacenamiento. La posible especialización de las digitaciones de la porción media del testículo del yaque, no ha sido reportada en otras especies, en las cuales se ha comprobado la presencia de zonas de transición.

La vesícula seminal (VS) es una estructura reproductiva accesoria presente en algunos peces teleósteos, principalmente en miembros de la familia Siluridae. La RD del testículo de yaque se caracterizó por contener secreciones acidófilas en el lumen y tejido glandular, sin formación de glándula conspicua. En algunos siluriformes de las familias Pimelodidae, Loricariidae y Callichthyidae, la actividad secretora ocurre también en la RD, con o sin formación de VS (Loir et al.). En peces de otras familias no siluriformes, han sido reportadas también la presencia de VS (Gobiidae) y glándulas testiculares
(Bleniidae) (Locatello et al., 2002; Richtarski \& Patzner, 2000).

Las secreciones presentes en el lumen, puede tener funciones similares a las que tienen las secreciones de VS presentes en otros grupos de teleósteos. La VS puede producir glicoproteínas neutras, hormonas esteroides y feromonas que incrementan el volumen del semen y pueden actuar en la fertilización y la atracción de las hembras (Resink et al., 1987; Santos et al., 2001; Singh \& Joy, 1998). Singh \& Joy (1999), analizaron la composición bioquímica de las secreciones de la VS de Clarias batrachus y encontraron que los niveles de proteínas totales, fructuosa, hexosaminas y ácido siálico, fueron más altos en el testículo maduro, al compararlas con las del testículo en descanso y sugirieron que la VS estaba especializada en secretar sustancias ricas en glicoproteínas para permitir almacenamiento temporal del semen. El hallazgo de tejido muscular liso y su naturaleza contráctil, constituyendo el ducto espermático en la porción distal de la RD, sugiere la presencia de un esfínter que podría estar limitando la salida del semen hacia la papila urogenital.

Se comprueba la alta capacidad de producción espermática que sucede en el testículo de yaque, que no es congruente con la poca cantidad que puede ser espontáneamente liberada por los machos de esta especie. Por lo tanto, se sugiere estudiar más detenidamente el efecto de la presencia de tejido contráctil en la vesícula seminal sobre la capacidad y facilidad para liberar el semen en esta especie.

\section{AGRADECIMIENTOS}

Los autores agradecen a Pedro René Eslava Mocha por su colaboración con los hallazgos histológicos, a Angélica Otero y Lili Marciales por su apoyo en la realización de los conteos y mediciones y a Ariel Marcel Tarazona por sus aportes en la corrección de este manuscrito.

MIRA, L. T. M.; MEDINA-ROBLES, V. M. \& CRUZ-CASALLAS, P. E. Testicular morphology of yaque Leiarius marmoratus (Pisces: Siluridae) in maturity reproductive stage. Int. J. Morphol., 28(2):421-426, 2010.

SUMMARY: Knowledge of the morphology and physiology of the testis, leads to generate bases for understanding the reproductive behavior of species, because the anatomical differences are related to reproductive performance. To contribute to biologic and reproductive knowledge of Yaque Leiarius marmoratus, anatomic, morphologic and functional characteristics of the testis in animals in a state of reproductive maturity were analyzed. In L. marmoratus, the testicles are located ventrally to the gas bladder and have many long finger-like structures that finish in spermatic duct. Microscopically it was found that the testis is espermatogonial unrestricted and tubular type, where the anterior portion presented spermatogenic activity, which diminishes in the medium portion and disappears in the caudal portion, leading to tissue with glandular secretory activity serving as a seminal vesicle. Inside each tubule of the testis, there are cysts containing sperm cells within the same stage of development. Based on microscopic features, were identified spermatocytes, spermatids and a large amount of free sperm into the lumen. Glandular cells were also identified, as well as smooth muscle tissue and epithelial tissue. In the spermatic duct (medium and distal portion), acidophilous secretion was abundant and in some regions were accompanied by free spermatozoa.

KEY WORDS: Catfish; Histology; Reproductive tract; Seminal vesicle. 


\section{REFERENCIAS BIBLIOGRÁFICAS}

Batlouni, S. R.; Romagosa, E. \& Borella, M. I. The reproductive cycle of male catfish Pseudoplatystoma fasciatum (Teleostei, Pimelodidae) revealed by changes of the germinal epithelium An approach addressed to aquaculture. Anim. Rep. Sci., 96:116$32,2006$.

Billard, R. Spermatogenesis and spermatology of some teleost fish species. Reprod. Nutr. Develop., 26:877-920, 1986.

Castillo, J. A. M.; Ramírez, L. R. \& Rodríguez, P. J. A. Ensayos de reproducción y alevinaje en Yaque Leiarius marmoratus (Gill, 1870) (Pises:Siluriformes:Pimelodidae) en la Orinoquia Colombiana. Memorias IV Seminario Internacional de Acuicultura I Congreso Nacional de Investigaciones Acuícolas, Septiembre 10-12, Bogotá, Colombia, 2003.

Grier, H. J. Cellular organization of the testis and spermatogenesis in fishes. Amer. Zool., 21:345-57, 1981.

Locatello, L.; Mazzoldi, C. \& Rasotto, M. B. Ejaculate of sneaker males is pheromonally inconspicuous in the black goby, Gobius niger (Teleostei, Gobiidae). J. Exp. Zool., 293:601-5, 2002.

Loir, M.; Cauty, C.; Planquette, P. \& Le Bail, P. Y. Comparative study of the male reproductive tract in seven families of SouthAmerican catfishes. Aquat. Living Resour., 2:45-56, 1989.

Lopes, D. C. J. R.; Bazzoli, N.; Brito, M. F. G. \& Maria, T. A. Male reproductive system in the South American catfish Conorhynchus conirostris. J. Fish Biol., 64:1419-24, 2004.

Mazzoldi, C.; Lorenzi, V. \& Rasotto, M. B. Variation of male reproductive apparatus in relation to fertilization modalities in the catfish families Auchenipteridae and Callichthyidae (Teleostei: Siluriformes). J. Fish Biol., 70:243-56, 2007.

Mora, J. A. \& Kossowski, C. Reproducción inducida del bagre yaque, Leiarius marmoratus, (Gil, 1870) con aplicación de LHRHa. XIII Congreso Venezolano de Producción e Industria Animal, Guarico, Venezuela, 2006.

Ramírez-Gil, H. \& Ajiaco-Martínez, R.E. Aspectos preliminares de la biología pesquera del yaque, Leiarius marmoratus (Gill, 1870) (Pisces: Siluriformes: Pimelodidae) en la parte alta del río Meta Orinoquia Colombiana. Bol. Cient. INPA:75-87, 1997.

Resink, J. W.; Van den Hurk, R.; Groeninx Van Zoelen, R. F. O. \& Huisman, E. A. The seminal vesicle as source of sex attracting substances in the african catfish, Clarias gariepinus. Aquaculture, 63:115-27, 1987.

Richtarski, U. \& Patzner, A. Comparative morphology of male reproductive systems in Mediterranean blennies (Blenniidae). J. Fish Biol., 56:22-36, 2000.
Santos, J. E.; Bazzoli, N.; Rizzo, E. \& Santos, G. B. Morphofunctional organization of the male reproductive system of the catfish Iheringichthys labrosus (Lütken, 1874) (Siluriformes: Pimelodidae). Tissue Cell, 33:533-40, 2001.

Santos, J. E.; Bazzoli, N.; Rizzo, E. \& Santos, G. B. Reproduction of the catfish Iheringichthys labrosus (Lütken) (Pisces, Siluriformes) in Furnas reservoir, Minas Gerais, Brazil. Rev. Bras. Zool., 21:193-200, 2004.

Singh, M. S. \& Joy, K. P. A comparative study on histochemical distribution of some enzymes related to steroid and glucuronide synthesis in seminal vesicle and testis of the catfish, Clarias batrachus. Zool. Sci., 15:955-61, 1998.

Singh, M. S. \& Joy, K. P. Annual correlative changes in some biochemical contents of seminal vesicle and testis in the catfish Clarias batrachus (L). Zool. Sci., 16:345-56, 1999.

Sneed, K. E. \& Clemens, H. P. The morphology of the testes and accesory reproductive glands of the catfishes (Ictaluridae). Copeia, 4:606-11, 1963.

Tan-Fermin, J. D.; Miura, T.; Adachi, S. \& Yamauchi, K. Seminal plasma composition, sperm motility, and milt dilution in the Asian catfish Clarias macrocephalus (Gunther). Aquaculture, 171:323-38, 1999.

Tavares-Dias, M.; Martins, M. L. \& Moraes, F. R. Relação hepatosomática e esplenosomática em peixes teleósteos de cultivo intensivo. Rev. Bras. Zool., 17:273-81, 2000.

Viveiros, A. T. M.; Eding, E. H. \& Komen, J. Effects of 17amethyltesterone on seminal vesicle development and semen release response in the African catfish, Clarias gariepinus. Reproduction, 122:817-27, 2001.

Viveiros, A. T. M.; Fessehaye, Y.; ter Veld, M.; Schulz, R. W. \& Komen, J. Hand-stripping of semen and semen quality after maturational hormone treatments, in African catfish Clarias gariepinus. Aquaculture, 213:373-86, 2002.

Vizziano, D.; Fostier, A.; Loir, M. \& Le Gac, F. Testis Development, its Hormonal Regulation and Spermiation Induction in Teleost Fish. Oxford, Alpha Science, 2008. p.465.

Dirección para correspondencia:

Tatiana M. Mira

Grupo de Investigación Biogénesis

Facultad de Ciencias Agrarias

Universidad de Antioquia

Medellín

COLOMBIA

Email: t.mirah@gmail.com

Recibido : 02-12-2009

Aceptado: 23-03-2010 